\title{
EVALUATING THE COMMAND CLIMATE IN MILITARY UNITS
}

\author{
Ananthan, $S$. \\ S.Inderjit
}

National Defence University of Malaysia, Kem Sungai Besi, Kuala Lumpur

\begin{abstract}
Military units are principally concerned with training and preparing for operations when they are not deployed on missions. During these periods when they are predominantly stationed in barracks, they are also occupied with a host of administrative and domestic tasks assigned by their higher formation. Despite the varied nature of day-to-day activities, heads of these units or commanders have the challenge of ensuring a suitable organisational climate (referred to as command climate) as this would inevitably contribute towards operational effectiveness. Unlike organisational climate, command climate is impacted by variables peculiar to military units. Existing literature indicates various psychological dimensions of operational effectiveness that includesmorale, group cohesion, confidence in leadership and job satisfaction. These variables have to be further verified through a systematic process i.e. scouring existing literature and conducting in-depth interviews with experienced commanders. Underlying theories impacting the various constructs will be identified to provide the necessary grounding. Subsequently,these intangible factors will be empirically measured. This research has its main objective of developing and validating a reliable and easy to use measurement tool, which would eventually enable military unit commanders to evaluate command climate as and when required.Higher formations will also be able to determine the ability of units to perform in the event they are deployed to undertake missions under stressful conditions.
\end{abstract}

Keywords : Organisational climate, command climate, morale, cohesion, job satisfaction.

\section{Introduction}

One of the major tasks during peacetime for defence organisations is to prepare for military operations. These operations may be in the form of routine assistance to civilian authority within the country or the more demanding task of defending the nation's territorial integrity during times of 
crisis and war. More frequently than ever, military forces are also required to operate abroad with coalition partners in peacekeeping and humanitarian relief operations. Military commanders thus have the task of ensuring that the organisations they command can perform effectively when called to undertake a wide range of missions.

To enhance organisational effectiveness, modern military forces are embracing greater levels of technology to improve their fighting and operational capability. However, commanders cannot depend on technology alone to produce a capable fighting force. Recent researches in militaries across the globe concur with evidence continually gleaned from business and industry that success is highly dependent on the quality of human workforce and their motivation (Murphy \& Fogarty, 2010). Thus, a military organisation's effectiveness in accomplishing military operations is very much dependent on how its personnel (men and women) are trained, gelled together and motivated. This in turn is reliant on a positive organisational culture and climate. More than ever before, organizational (command) climate has become an increasingly significant prerequisite for unit effectiveness and combat readiness (Jones, 2003).

This paper has its main objective to discuss the concept of command climate in military organisations. It will be limited to army units and not discuss the challenges for climates in other defence and security agencies. This paper endeavours to determinetwo aspects; 1 ) The dimensions of military command climate, and 2) The development of a measurement instrument.

\section{Scope}

This research will initially be carried out within the Malaysian Army infantry units only. Command climates within these units are unique.The major thrust of the research will be to design a measurement tool to evaluate command climate during peacetime and barrack duties. The instrument developed through this research will only be able to measure command climate infull-deployment or combat missionswith further modification.

\section{Existing Climate Surveys}

Command climate surveys have become a routine and important activity for many modern defence forces. Though they may take different forms, their fundamental objective is the same i.e. to measure the possible readiness and eventual effectiveness of combat units, in particular, to undertake military operations. The US Army requirescommanders to carry out a Command Climate Survey to evaluate their unit's work environment upon assuming command. This survey is to be repeated from time to time as required by policy(US Army Headquarters, 2008). It is a 24-item instrument 
which measures responses in various scales. There is also a separate section that requests for qualitative data. The UK Ministry of Defence uses the Armed Forces Continuous Attitude Survey (AFCAS) designed to collect information on attitudes and opinions of serving military personnel. However each service of the armed forces is given a slightly separate format which is able to tap individual responses based on varied roles and experience. It is essential done online with 100 items measured in various scales.

More detailed information is available of a unit climate survey used by the Australia Defence Forces since 2004.Known as the Profile of Unit Leadership, Satisfaction and Effectiveness (PULSE) survey, it provides a snapshot on the status of morale of unit and sub-units. It is intended to inform commanders on the motivational levels of their personnel and factors that influence this outcome (Goyne, 2010).The PULSE delineates response at the tri-level of individual, group and unit. The core constructs measured are job stress, work motivation, job satisfaction, satisfaction with communication, confidence in leadership, teamwork or cohesion, organisational support and organisational commitment. Thus far the PULSE survey is well received by commanding officers in the Australian Defence Force and unit members are happy to respond to subsequent surveys when they realize their feedback through this survey are acted upon.

It can be concluded from the overall analysis of existing surveys that each military force employs instruments that are best suited to their respective needs. Further to that, not much information can be gleaned from the essential constructs that need to be measured and corresponding data analysis method. Due to this, it would be best to refer to other forms of literature to design an initial framework for the purpose of developing a purpose-designed scale.

\section{Key Concepts of Command Climate}

In this section, definitions of the various concepts and constructs will be framed and subsequently preliminary thoughts on their interrelationships will be outlined.Concepts related to organisational climate should provide a useful reference for the measure of command climate, as they are both the same constructs but operationalised in different environments.

\section{Climate}

Climate is a complex construct. Many studies tend to describe organisational climate and culture as one concept or culture being a sub-set of climate (Rosseau, 2011).However, Schneider (1985) suggests that climate denotes activities and processes while culture relates to the shared norms and values. Similarly, Watkin and Hubbard (2003) propose that organisational climate is "a measure of employees' perception of those aspects of their 
environment that directly impact how well they can do their jobs'”. Another, more elaborate, definition of organisational climate is offered by Bowen and Ostroff (2004). They define organizational climate as shared perceptionsamong employees of what the organization is like in terms of practices, policies, procedures, routines, and rewards. In the military the commander of a unit, by virtue of authority given to him, is solely responsible for the climate of his organisation (Doty \& Gelineau, 2008). A positive command climate is essential to building a disciplined, efficient, well-run unit capable of accomplishing assigned tasks. This must be done in concert with establishing a disciplined process by which effective communication throughout the chain of command can occur (Edson, 2011). In the context of this research, army infantry units are known to possess the same basic organisational culture. Despite this fundamental similarity, the productivity and eventual effectiveness of each unit can differ vastly. Academic literature attributes this to individual and collective motivation influenced fundamentally by command (organisational) climate created largely by the commanders and senior members of the unit.

\section{Morale and Motivation}

Morale and motivation are two peculiar concepts. Both morale and motivation can be a measure of command climate as well as an outcome of positive climate. Britt and Dickinson (2005) state that morale in the military is indicative of a service member's level of motivation and enthusiasm for accomplishing a mission. Similarly, shared perceptions of undesirable organisational state of affairs,can contribute to low moraleand hence low motivation to work.However, when the overall climate creates a conducive and vibrant working environment, morale and motivation can be high. Manning (1991), argues that morale has sharply different meanings depending on thecontext. The US Army manual on Leadership (2006) provides a clearer illustration of military morale:

"Morale is the human dimension's most important intangible element. It is a measure of how people feel about themselves, their team, and their leaders. High morale comes from good leadership, shared effort, and mutual respect".

This definition suggests that morale in not only an individual feeling but reflective of the entire team or group feel about themselves that eventually creates the motivation and enthusiasm to perform their tasks. When group members feel respected and perceive their commanders to be doing a good job, morale and motivation can be expected be high. 


\section{Cohesion}

In evaluating unit climate, the Australian PULSE model taps the perception of both task and group or social cohesion (Goyne, 2009). Task cohesion is defined as:

"...the shared commitment among members to achieving a goal thatrequires the collective efforts of the group. A group with high task cohesion is composed of members who share a common goal and who are motivated to coordinate their efforts as a team to achieve that goal". On the other hand, social cohesion is the extent to which group members like each other, prefer to spend their social time together, enjoy each other's company, and feel emotionally close to one another"(MacCoun and Hix, Undated).

It would be best if a group can have both task and social cohesion. An indicator of this is when group members spend a lot of time working, playing, training and participating in leisure activities together. The military in general (and the infantry in particular) has a deliberately powerful socialisation system. These socialising influences and develops group cohesion and highly motivated teams for necessary for group survival and successful missions (Pinch, 2006).

\section{Confidence in leadership}

In the military, the Commanding Officer as the CEO of a unit has the authority and responsibility for establishing the leadership climate and developing disciplined and cohesive units (US Army Headquarters, 2008). Literature is abound with studies that link leadership and participative management with employee satisfaction. Many studies report of employees pointing tonon-supportive group and leader relations as causes of stressful organisational climates. (Rosseau, 2011; Schneider, 1985).A study undertaken at the US Naval Academy (Miller, 2006) suggests that leadership characteristics that are centered on equality and fairness have significant influence on a unit's morale and hence job performance. Similarly, Jones (2003) stressed the importance of leader trustworthiness as major contributor of command climate. As leadership is all about change and getting theorganisation from "here to there", people would rather follow a commander who they have confidence in leading them especially where there is great risk to life and limb.

\section{Job Satisfaction}

Any research that studies employee perception of their work place can be considered as a climate study. Most widely studied are the relationship of climate to employee well-being such as job satisfaction and job stress (Rosseau, 2011). Job satisfaction is the combination of feelings 
and beliefs that workers hold in relation to their current jobs. Someone with a high level of satisfaction will generally like their job. They feel that they are being fairly treated and believe that the job has many desirable facets. The satisfaction at work has been characterized as a positive or pleasing emotional state that emerges as the result of evaluating one's work or experiences in the workplace. (Locke, 1976). Job satisfaction is the degree to which people like their jobs. Some people enjoy work and find it to be a central part of life. Others hate to work and do so only because they must. The study of the causes and consequences of these important issues is one of the major domains of organizational psychology. Job satisfaction is directly related to job performance, attitude, motivation and morale. Job dissatisfaction was predicted by lack of career opportunities, poor organizational climate and morale and lack of autonomy at work, together with some domestic stressors e.g. family health” (Cooper \& Sloan, 1985).

\section{Job Performance}

Job performance can be defined as how well a worker executes job related tasks and activities (Schneider, 1985). As in all other spheres of the work environment, the military carries out annual evaluation of personnel as a way of monitoring job performance. The Australian PULSE model places job performance as an importance outcome unit climate (Goyne, 2010). However, personnel responding to the PULSE survey are required to do selfappraisal of how well they are performing their job. This is in conflict with what is generally known in social science research as rater-bias. Sekaran and Bougie (2010) suggest that rater reliability is an important issue which should be addressed through more objective and precise criteria of measurement. Job performance can also be based on annual evaluation reports made by superiors. There is a need to weigh these two options.

\section{Conceptualising the Measurement of Command Climate}

Each of the concepts defined in the preceding paragraphs has the potential to predict job performance as an outcome. Based on the definitions and relationships established thus far, an initial conceptual model to aid the research is proposed as follows:

Command Climate

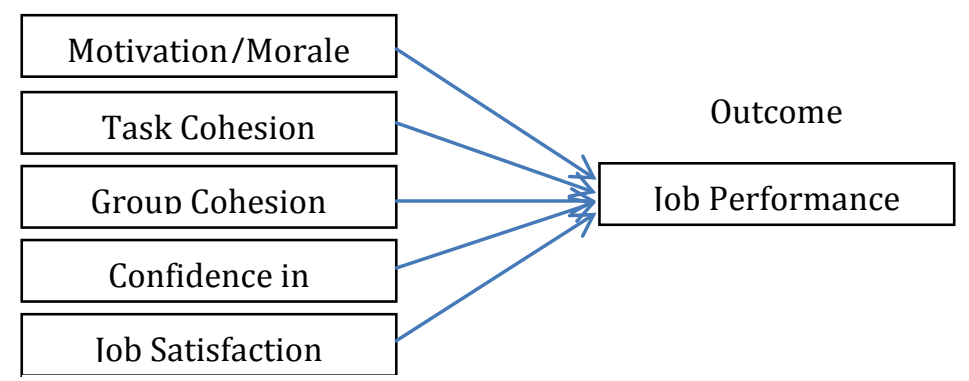

Figure 1: Conceptual Model for Measurement of Command 


\section{Research Method}

To undertake this research, prior permission will have to be requested from Army Headquarters (Human Resource Branch). Their agreement and support is essential to the cooperation from commanding officers of targeted military units and respondents. As this is an exploratory study, the instrument will have to be designed taking into consideration the peculiarities of the Malaysian Army. Patton's (2002) suggestion that a triangulation method be used to check and establish validity of findings from multiple perspectives will be adhered. This is in an endeavour to overcome the weaknesses and biases from using a single method, single-observer and single-theory studies.

Towards this end, four distinct steps shall be followed in designing and constructing the survey questionnaire to meet scientific rigour and standards. First, based on the conceptualisation of command climate gleaned from relevant literature, each sub-domain will be operationalised. Care will be taken to ensure each construct can be measured. Where possible the existing questionnaires from past related studies will be sourced. Secondly, requirement, a focus group discussion shall be arranged at the Army Headquarters to obtain inputs on the concepts of command climate and its operationalization. The theoretical model will be presented to experts ensure face validity. This will inevitably involve senior officers who have experienced peacetime and operational command. Thirdly, interviews and discussions will be carried out with senior rank and file personnel currently serving in infantry units. They are the people who experience command climate first hand. Their views on positive and negative contributors of command climate will be solicited. Collectivelythis information from literature, focused group discussions and interviews will be triangulated in designing the required survey instrument. Finally, to ensure high content validity, an army psychiatrist and expert on test construction will be sought to help verify each item of the instrument. Factors such as respondents military experience (numbers of years of service), language proficiency and understanding of the various terminologies are important criteria in the overall design of the test.

\section{Research Ethics}

To obtain genuine feedback and participation, respondents must be given the assurance that they can provide honest and direct but anonymous feedback to their commander. Thus, it is important to ensure the highest standards of confidentiality in this research especially as it requires respondents to share information about the impact of their superior's performance within the organisation. Responses shall be treated with the strictest of confidence with assurance that no one accept the researchers will 
see the completed survey. Completed surveys must be safely stored and destroyed appropriately within an agreed time.

\section{Conclusion}

Many western defence forces have been using some form of survey to quantify command climate to seek greater assurance of operational effectiveness. Indeed the report generated by this survey will be helpful to unit commanders to determine the different actions to be taken to improve the climate within their units. It will also help higher commanders to ascertain the potential readiness of a given unit under their command. This is an exploratory study and a first of its kind in the Malaysian Army. It is hoped that this can be a pivotal study for further research on command climate in the Malaysian military environment. The empirical evidence collected from the study shall be able to provide a foundation for the development of a robust instrument for evaluating the command climate of infantry units in Malaysian Army.

\section{References:}

Bowen, D.E. \& Ostroff, C. (2004).Understanding HRM-from performance linkages: The role of the strength of the HRM system.Academy of Management Review,29(2), 203-221.

Cooper, C.L. \& Sloan, S. (1985). Occupational and psychosocial stress among commercial aviation pilots.Journal of Occupational Medicine, 27, 570-6.

Doty, J., \& Gelineau, J. (2008).Command climate.Army Magazine,58(7).

Edson, D.W. (2011). Command climate.Marine Corps Gazette, 95(7).

Goyne, A. (2009). PULSE project overview: Pulling the strings of unit climate together. Paper presented at the $10^{\text {th }}$ Industrial and Psychology Conference. Retrieved from http://www.iopconference.com.au/2009/presentations/2_Friday/1200/GoyneA.pdf Goyne, A. (2010). Maximizing performance: Measuring unit climate in the Australian defence https://www.psychology.org.au/publications/inpsych/2010/april/goyne/ Goyne, A. (Undated). Measuring unit effectiveness: What do commanders want to know and why?

Jones, S.M. (2003). Improving accountability for effective command climate: A strategic imperative.The United States Army War College Press. Retrieved from http://www.strategicstudiesinstitute.army.mil/pubs/display.cfm?pubID=248 
Locke, E.A. (1976). The nature and causes of job satisfaction.In Dunnette, M.D. (Ed), Handbook of Industrial and Organizational Psychology.12971349. Chicago; Rand McNally.

MacCoun, R.J., \& Hix, W. M. (Undated), Unit cohesion and military performance. $\quad$ Retrieved from http://www.law.berkeley.edu/files/csls/Unit_Cohesion_and_Military_Perfor mance_Ch5_MacCoun_Hix.pdf

Miller, C.A. (2006). The influence of midshipmen leadership on morale at the United States Naval Academy (Unpublished master's thesis).Naval Postgraduate School, California, United States.

Murphy, P.,\& Fogarty, G. (2010). Good to Go. The human dimensions of mission readiness.Retrieved fromhttp://eprints.usq.edu.au/6123/1/Murphy_Fogarty_BookCh_A_PV.pdf. Patton, M.Q. (2002). Qualitative Research and Evaluation Methods. Thousand Oaks, CA: Sage Publications.

Pinch, F.C. (2006). An introduction to challenge and change in military: Gender and diversity issues. In Pinch, F.C., MacIntyre, A.T., Brown, P., \& Okros, A.C. (Eds), Challenge and change in military: Gender and diversity issues. Ontario; Canadian Defence Academy Press.

Rosseau, D.M. (2011). Organisational climate and culture. Retrieved from http://www.ilo.org/oshenc/part-v/psychosocial-and-organizational-

factors/macro-organizational-factors/item/29-organizational-climate-andculture.

Schneider, B. (1985). Organizational behaviour.Annual Review of Psychology, 36, 573-611.

Sekaran, M. \& Bougie, R. (2010).Research Methods for Business.John Wiley and Sons. NY.

Watkin, C. Hubbard, B. (2003). Leadership motivation and the drivers of share price: The business case for measuring organizational climate. Leadership \& Organization Development Journal,24(7), 380-386.

US Army Headquarters. (2006). Army leadership: Field Manual 6-22, 7-8. US Army Headquarters. (2008). Army command policy: Army regulation 600-20, 53. 